\title{
Advances in Meniscal Tissue Engineering
}

\author{
Umile Giuseppe Longo, ${ }^{1,2}$ Mattia Loppini, ${ }^{1,2}$ Francisco Forriol, ${ }^{3}$ Giovanni Romeo,, ${ }^{1,2}$ \\ Nicola Maffulli, ${ }^{4}$ and Vincenzo Denaro ${ }^{1,2}$
}

${ }^{1}$ Department of Orthopaedic and Trauma Surgery, Campus Bio-Medico University of Rome, Via Álvaro del Portillo 200, 00128 Rome, Italy

${ }^{2}$ Centro Integrato di Ricerca (CIR), Università Campus Bio-Medico di Roma, Via Álvaro del Portillo 21, 00128 Rome, Italy

${ }^{3}$ University CEU San Pablo, 28003 Madrid, Spain

${ }^{4}$ Centre for Sports and Exercise Medicine, Barts and The London School of Medicine and Dentistry, Mile End Hospital, 275 Bancroft Road, London E1 4DG, UK

Correspondence should be addressed to Umile Giuseppe Longo, g.longo@unicampus.it

Received 21 July 2011; Accepted 26 August 2011

Academic Editor: Wasim S. Khan

Copyright () 2012 Umile Giuseppe Longo et al. This is an open access article distributed under the Creative Commons Attribution License, which permits unrestricted use, distribution, and reproduction in any medium, provided the original work is properly cited.

Meniscal tears are the most common knee injuries and have a poor ability of healing. In the last few decades, several techniques have been increasingly used to optimize meniscal healing. Current research efforts of tissue engineering try to combine cell-based therapy, growth factors, gene therapy, and reabsorbable scaffolds to promote healing of meniscal defects. Preliminary studies did not allow to draw definitive conclusions on the use of these techniques for routine management of meniscal lesions. We performed a review of the available literature on current techniques of tissue engineering for the management of meniscal tears.

\section{Introduction}

The menisci of the knee are two fibrocartilaginous Cshaped discs interposed between the femoral and tibial joint surfaces. They provide shock absorption, stabilization, lubrication, load distribution, and joint filler supplying femoral-tibial incongruity $[1,2]$. Traumatic lesions of the menisci are common and induce changes in biomechanical behaviour of the joint affecting the load distribution and contact stresses [3]. The healing process of torn menisci depends on their morphologic features. Each meniscus consists of outer vascular part and inner avascular part. The vascular supply is an important factor to determine the potential healing of meniscal tears [4]. Therefore, lesions of the outer one-third of the meniscus are believed to have the greatest capacity for repair. Meniscal tears are usually located in the inner avascular part of the meniscus and are not able to heal spontaneously. Several strategies to repair and replace meniscus have been proposed, but only few of them have been shown to be effective [5-9].
Depending on the type of lesion, surgical approaches include total or subtotal meniscectomy, transplantation, and repair [10]. As the fibrocartilaginous tissue of the meniscus presents a limited regenerative capacity, new approaches are required to improve meniscal healing. In the last few decades, several emerging strategies, including growth factors, gene therapy, and application of mesenchymal stem cells (MSCs), have been proposed to increase healing of a damaged meniscus by tissue-engineered constructs. Tissue engineering is based on a combination of cells, growth factors, and scaffolds able to stimulate the meniscal healing $[11,12]$.

We performed a review of the available literature on current techniques of tissue engineering for the management of meniscal tears.

\section{Cells Transplantation}

Human menisci are populated by different cell types that might respond differently to various stimuli released from 
the matrix $[13,14]$. Cell-based therapy has significantly contributed to develop tissue-engineering strategies consisting of cells-scaffold constructs able to promote healing in an avascular environment [15]. Autologous fibrochondrocytes are one of the cell types used in meniscal repair. Fibrochondrocytes are able to proliferate and produce new extracellular matrix (ECM) [16]. The amount of glycosaminoglycans (GAGs) produced by fibrochondrocytes from the inner avascular part is more than the amount produced from a peripheral fibrous location when seeded into a porous collagen scaffold $[17,18]$. Although these findings are encouraging, the application of autologous fibrochondrocytes in meniscal tissue engineering is limited by the difficulty to harvest a sufficient number of cells.

An alternative cell type used to promote the healing of meniscal lesions is the articular chondrocyte $[19,20]$. Peretti et al. [19] described a porcine chondrocyte model where implantation of such cells was performed in the avascular part of the meniscus, using an allogenic scaffold seeded with autologous chondrocytes, showing that these chondrocytes were able to heal a meniscal tear [19]. Another potential cell therapy approach is represented by MSCs. These pluripotent cells are able to differentiate into specific therapeutic cell types (developmental plasticity) [21-23].

The effects of extrinsic stimuli (biochemical, physical, and mechanical) from the microenvironment, within a cell/scaffold combination, are a promising alternative for repairing large meniscal defects [24]. Several studies confirm production of abundant extracellular matrix around the cells, restoring a meniscal-like tissue in the avascular zone [25-28]. In particular, the combination of growth factors and mesenchymal stem cells within scaffold implants increased proteoglycan and/or collagen synthesis [26, 28, 29].

The effect of load on all these different cell types becomes an interesting field for future research. Moreover, their stimulation with the application of growth factors in combination with a mechanically loadable scaffold has been proposed as the focus of future studies.

\section{Growth Factors}

Growth factors typically act on target cells as signalling molecules, promoting cell differentiation and chondrocytic proliferation [30]. They also stimulate the synthesis and inhibit degradation of (extracellular matrix) ECM by a mechanism of downregulation of proteases [31]. Several growth factors have been demonstrated to have an effect on the healing of tears and on ECM synthesis in tissue and cell culture. In particular, transforming growth factor$\beta 1$ (TGF- $\beta 1$ ) seems to have several regulatory activities to stimulate the production of extracellular matrix and collagen type II by meniscus cells $[30,32]$. Application of this growth factor has resulted in the synthesis of specific proteoglycans to enhance both collagen and GAGs production and their biomechanical properties $[33,34]$. Pangborn and Athanasiou [35] used TGF- $\beta 1$ to have consistent effects on collagen and proteoglycan production by meniscal cells.
TGF- $\beta 1$ was applied to monolayer cultures for 3 weeks and generally showed a higher production of each ECM component.

Fibroblast growth factor-2 (FGF-2) is another important factor found in the cartilaginous matrix. It enhances proliferation of the joint chondrocytes, mesenchymal stem cells, osteoblast, and adipocytes. In addition, FGF can also maintain the ability of any cell types to differentiate [36, 37]. Recently, FGF-2 has been vectored with recombinant adenoassociated virus (rAAV) [38]. Histology demonstrated enhanced cell proliferation and expression of the $\alpha$-smooth muscle actin ( $\alpha$-SMA) contractile marker, but it did not significantly enhance the synthesis of major extracellular matrix components or DNA contents.

Other authors have identified basic fibroblast growth factor (bFGF) as effective at stimulating extracellular matrix production in cell and tissue development. The ovine experimental model showed the presence of meniscal fibrochondrocytes responding to bFGF by proliferating and producing new extracellular matrix [16].

The insulin growth factors (IGFs), particularly IGF-1, are considered the main anabolic growth factor of articular cartilage $[39,40]$. IGF-1 stimulates the synthesis of proteoglycans, collagen II, and integrins. In a recent study, the effects of three growth factors regimens was examined: basic fibroblast growth factor (bFGF) alone, bFGF plus transforming growth factor (TGF- $\beta 1$ ), and IGF-1 [41]. The mixture of growth factors showed an upregulation of collagen II and aggrecans under the effects of TGF- $\beta 1$ and IGF- 1 that may be an important cellular response to mediate avascular meniscal healing.

The induction of angiogenesis is an important factor to stimulate the poor potential healing of meniscal tears. The vascular endothelial growth factor (VEGF) may promote better healing, stimulating angiogenesis to improve the healing capacities of meniscus tissue. However, a study by Petersen et al. did not lead to satisfactory results, and the local application of VEGF did not promote meniscus healing [42].

Bone morphogenetic proteins (BMPs) are members of the TGF- $\beta$ superfamily and play an important role during embryogenesis and tissue repair by their osteoinductive properties $[43,44]$. BMP-2 acts as a stimulus in the differentiation of mesenchymal cell. It also presents a migratory effect in endothelial cells or smooth muscle cells, but rarely in chondrocytes. Alternatively, BMP-7 can have a function in regulating matrix homeostasis and can inhibit the degradation processes. BMP-7 acts with different chondrogenic agents and is more effective than BMP-2 for chondrogenic differentiation of MSCs [45]. Minehara et al. [46] developed a new technique for seeding chondrocytes onto solvent-preserved human meniscus using the chemokinetic effect of recombinant human bone morphogenetic protein2 (rhBMP-2) on chondrocytes seeded into solvent-preserved human meniscus. After a 3-week incubation, a natural chemokinetic effect of rhBMP-2 promoted migration and proliferation of chondrocytes. These findings demonstrate that BMPs induce a marked cellular response to improve meniscal repair. 


\section{Preparations Rich in Growth Factors}

The application of growth factors has been proven to be effective for meniscal healing. Recently, platelet-rich plasma (PRP) may be better than the use of isolated growth factors. PRP is an autologous substance rich in platelets. It is easily prepared by spinning autologous blood in a centrifuge to form a dense fibrin matrix that can be placed directly at the meniscal repair site $[47,48]$. Ishida et al. reported the regenerative effects of platelet-rich plasma in a rabbit model [49]. Cultured meniscal cells were prepared to assess proliferative pattern under the exposure to PRP. Histological findings showed the healing properties of PRP in extracellular matrix synthesis and cell proliferation.

\section{Biomaterial Used in Tissue Engineering}

Tissue engineering techniques using novel scaffold materials offer potential alternatives for managing meniscal tears. An ideal scaffold should have the basic structure of the meniscus, and it should be biodegradable and bio-reabsorbable in the long term. Probably, the most important functions are the induction of cell proliferation and production of extracellular matrix, using it as a carrier for stimulatory and inhibitory growth. The structure should be strong enough to withstand the load in the joint and maintain its structural integrity without damaging the articular cartilage $[15,31$, 50-52].

Several materials used to fabricate scaffolds (natural or synthetic) may be considered for application in tissue engineering of the meniscal healing. The first to be developed are natural scaffolds as periosteal tissue, perichondral tissue, collagen, small intestine submucosa, silk, and meniscus tissue itself [53].

A multilayered (tribiological), multiporous silk scaffold system to mimic native meniscus architecture and shape was described [54]. Silk constructs showed a good biocompatibility with a florid chondrogenesis as well as other tissues [54-57]. The cells (human articular chondrocytes and dermal fibroblast cells) were seeded onto the silk scaffold in association with human chondrocytes for 28 days. Histological analysis showed an increase production of GAGs and proteoglycans and a colonization of ECM similar to native tissue from fibroblasts and chondrocytes.

Minehara et al. developed a cell-seeding technique using a solvent-preserved human meniscus as a scaffold [46]. The chondral cells were treated with recombinant human bone morphogenetic protein-2 (rhBMP-2) and cultured for 3 weeks. The histological and immunohistochemical analyses indicated that this repair tissue was mainly fibrous. Moreover, results suggest a potential application of rhBMP2 as a natural chemokinetic factor into a scaffold for tissue engineering.

Collagen scaffolds have been also examined for tissue engineering of the meniscus. Meniscus cells seeded in these scaffolds may express alpha-smooth muscle actin $(\alpha-$ SMA) that has contractile capacities. This demonstrates the potential healing in wound contraction, but other physiological and pathological processes are still unknown
$[58,59]$. Mueller et al. studied collagen type I and II scaffolds seeded with canine fibrochondrocytes for 21 days [60]. Type II scaffold contained up to $50 \%$ more GAGs than type I scaffold. A limit of the collagen scaffolds may be their poor mechanical properties, as the shape of the construct cannot be varied.

The use of synthetic polymer-based scaffolds is a novel option offering the potential of earlier healing. Stewart et al. [61] used polyglycolic acid (PGA) scaffolds seeded with ovine meniscal chondrocytes. The cells were seeded onto the PGA scaffold in the presence of platelet-derived growth factor- (PDGF-) AB, PDGF-BB, insulin-like growth factor(IGF-) I, transforming growth factor-betal (TGF- $\beta 1$ ), and basic fibroblast growth factor (bFGF) and evaluated after 39 days. Histological analysis of sections from ovine meniscal chondrocytes PGA scaffolds did not show any difference in GAG or collagen production between the treatment groups. However, immunohistochemical analysis demonstrated a different expression of collagen production: the production of collagen type I was increased, whereas the collagen type II was decrease at day 39 in all constructs functionalized with growth factors. A concomitant high infiltration of cells was also found.

Another tissue-engineered strategy consists in a poly-Llactic acid (PLLA) scaffold used in association with culture of meniscus cells and bFGF under hypoxic conditions [62]. After 4 weeks, histological evaluation demonstrated the presence of collagen and GAG, probably due to synergic effects of hypoxia and bFGF. An earlier study by Ionescu tested the effects of TGF- $\beta 1$ as a function of age, on proliferation of bovine meniscus fibrochondrocytes (MFCs) in a polycaprolactone (PCL) cylindrical scaffold [63]. Even though the results indicated a loss of proliferation and migration capacity with aging, the addition of TGF-b showed better maintenance of overall explant properties.

\section{Gene Therapy}

Gene therapy is considered an alternative strategy to develop future protocols for tissue engineering of meniscus tissue, using viral or nonviral vectors or direct gene transfer [64, 65]. In this way, the transfer of genes used to encode healing factors is a valid technique to apply growth factors to the site of injury for extended period. The vectors most frequently used in meniscal lesion are adenovirus, adenoassociated virus (AAV), and retrovirus. Nonviral vectors are not indicated because of being less efficient, although they are less pathogenic. Viral vectors allow the insertion of genes into death cells and the production of growth factors.

Previously, we mentioned a study where FGF-2 in association with recombinant adenoassociated virus (rAAV) vectors were used [38].

Goto et al. [66] developed a gene therapy strategy based on monolayer cultures of human and canine meniscal cells infected with retroviruses carrying human TGF- $\beta 1$ cDNA or marker genes. There was an increased synthesis of collagen and proteoglycan in response to the addition of TGF- $\beta 1$. 
Another possible technique for gene transfection is the injection of adenovirus vector encoding the hepatocyte growth factor gene (AdHGF) in cell-seeded bovine PGA scaffolds [67]. This strategy showed the formation of vascularised fibrous tissue by 2 weeks and vascularized meniscuslike tissue in 8 weeks. The authors concluded that gene transfer techniques could be used to induce blood vessel formation in tissue engineering meniscus samples.

\section{Discussions}

Application of tissue engineering is a promising alternative approach for the management of meniscus injuries. Advances in meniscal tissue engineering focus on the use of different cell sources, scaffolds, growth factors, or a combination thereof. The potential effect of cell-based therapy for meniscal tears could improve healing of lesion in the avascular zone and expand the indication for repair rather than removal. A variety of cell types such as autologous fibrochondrocytes, articular chondrocytes, and MSCs are available in large quantities into the body and can be used in tissue engineering [17-19,28]. Of these, progenitor cells such as mesenchymal stem cells have the advantage to be easily expandable without the loss of their differentiation potential into a variety of mesenchymal tissues [68-80] including bone, tendon, cartilage, muscle, ligament, fat, and marrow strom $[13,21,22]$. Probably, the application of MSCs might be a better cell source than fibrochondrocytes for meniscus repair.

The long-term biochemical and biomechanical features of tissue engineering techniques are determined by a combination of a well-integrated cell population with a scaffold. The development of carrier scaffolds should provide mechanical stability of the meniscus, maintaining its structural integrity without damaging the articular cartilage $[15,51]$. Several scaffold implants have been investigated in the management of meniscal tears.

The use of growth factors has been demonstrated to have an effect on the healing of tears and on ECM synthesis in tissue and cell culture [30,61]. Direct introduction of growth factors, such as TGF- $\beta$, BMPs, IGF-1, FGF, and VEGF, has positively influenced the clinical outcome of the meniscal repair procedures $[33,59,81]$. Previous studies have demonstrated that the effects of TGF- $\beta 1$ and BMPs have a better potential to help healing in tissue engineering $[34,45,46]$. The focus in this future research should be on the assessment of a mechanically loadable scaffold that retains growth factors and at the same time is degraded to allow revascularisation.

Alternatively, gene transfer techniques represent a favorable strategy for growth factor delivery, inducing vascularisation of tissue-engineered constructs $[66,67,81]$. Several viral vectors expressing therapeutic proteins such as growth factors have been investigated to assess their potential to improve remodelling and healing of meniscus. Although gene therapy is a relatively new field in tissueengineered menisci, it is one of the treatment options in the future.

\section{Conclusion}

The importance of the meniscus in safeguarding joint function has gained a considerable interest in the recent years. The current therapeutic strategy to treat meniscal defects is partial or total meniscectomy, but this may predispose patients, especially younger individual, to early osteoarthritis changes. The management of meniscal pathology to promote a healing response is considered essential in dealing with these injuries. When possible, meniscal repair should be performed to try to maintain meniscal integrity and prevent long-term degenerative changes.

New therapeutic strategies of meniscal replacement and tissue engineering need to be developed, but they are still at their infancies [11, 12]. The first step, the need to develop autologous grafting procedure, consists in finding the best cell source for meniscus repair, which to date seems to be the MSCs. The second step consists in fabricating an opportune biological scaffold which is able to carry cells into the meniscal lesion and to allow their differentiation, proliferation, and ECM synthesis to produce a meniscal native-like tissue. The biological activity of scaffold should be implemented through its functionalization with growth factors, such as TGF- $\beta 1$ and BMPs.

Further research is necessary to successfully address the difficult problem of meniscal regeneration. Advancements in this field should be strongly encouraged, because of autologous grafting through either tissue engineering for repair or that complete replacement following excision represents a suitable alternative to partial or total meniscectomy or cadaveric implants.

\section{References}

[1] P. Ghosh and T. K. F. Taylor, "The knee joint meniscus. A fibrocartilage of some distinction," Clinical Orthopaedics and Related Research, no. 224, pp. 52-63, 1987.

[2] K. Messner and J. Gao, "The menisci of the knee joint. Anatomical and functional characteristics, and a rationale for clinical treatment," Journal of Anatomy, vol. 193, part 2, pp. 161-178, 1998.

[3] M. Englund, E. M. Roos, H. P. Roos, and L. S. Lohmander, "Patient-relevant outcomes fourteen years after meniscectomy: influence of type of meniscal tear and size of resection," Rheumatology, vol. 40, no. 6, pp. 631-639, 2001.

[4] J. Klompmaker, R. P. H. Veth, H. W. B. Jansen et al., "Meniscal repair by fibrocartilage in the dog: characterization of the repair tissue and the role of vascularity," Biomaterials, vol. 17, no. 17, pp. 1685-1691, 1996.

[5] B. Johnstone, T. M. Hering, A. I. Caplan, V. M. Goldberg, and J. U. Yoo, "In vitro chondrogenesis of bone marrow-derived mesenchymal progenitor cells," Experimental Cell Research, vol. 238, no. 1, pp. 265-272, 1998.

[6] S. P. Arnoczky and R. F. Warren, "The microvasculature of the meniscus and its response to injury. An experimental study in the dog," American Journal of Sports Medicine, vol. 11, no. 3, pp. 131-141, 1983.

[7] Z. N. Zhang, K. Y. Tu, Y. K. Xu, W. M. Zhang, Z. T. Liu, and S. H. Ou, "Treatment of longitudinal injuries in avascular area of meniscus in dogs by trephination," Arthroscopy, vol. 4, no. 3, pp. 151-159, 1988. 
[8] J. Port, D. W. Jackson, T. Q. Lee, and T. M. Simon, "Meniscal repair supplemented with exogenous fibrin clot and autogenous cultured marrow cells in the goat model," American Journal of Sports Medicine, vol. 24, no. 4, pp. 547-555, 1996.

[9] Z. L. Szomor, T. E. Martin, F. Bonar, and G. A. C. Murrell, "The protective effects of meniscal transplantation on cartilage: an experimental study in sheep," Journal of Bone and Joint Surgery, Series A, vol. 82, no. 1, pp. 80-88, 2000.

[10] J. J. Klimkiewicz and B. Shaffer, "Meniscal surgery 2002 update: indications and techniques for resection, repair, regeneration, and replacement," Arthroscopy, vol. 18, no. 9, pp. 14-25, 2002.

[11] U. G. Longo, A. Lamberti, N. Maffulli, and V. Denaro, “Tendon augmentation grafts: a systematic review," British Medical Bulletin, vol. 94, no. 1, pp. 165-188, 2010.

[12] U. G. Longo, A. Lamberti, N. Maffulli, and V. Denaro, “Tissue engineered biological augmentation for tendon healing: a systematic review," British Medical Bulletin, vol. 98, no. 1, pp. 31-59, 2011.

[13] P. C. M. Verdonk, R. G. Forsyth, J. Wang et al., "Characterisation of human knee meniscus cell phenotype," Osteoarthritis and Cartilage, vol. 13, no. 7, pp. 548-560, 2005.

[14] C. Stärke, S. Kopf, W. Petersen, and R. Becker, "Meniscal Repair," Arthroscopy, vol. 25, no. 9, pp. 1033-1044, 2009.

[15] S. B. Adams Jr., M. A. Randolph, and T. J. Gill, "Tissue engineering for meniscus repair," The Journal of Knee Surgery, vol. 18, no. 1, pp. 25-30, 2005.

[16] N. S. Tumia and A. J. Johnstone, "Promoting the proliferative and synthetic activity of knee meniscal fibrochondrocytes using basic fibroblast growth factor in vitro," American Journal of Sports Medicine, vol. 32, no. 4, pp. 915-920, 2004.

[17] K. Nakata, K. Shino, M. Hamada et al., "Human meniscus cell: characterization of the primary culture and use for tissue engineering," Clinical Orthopaedics and Related Research, no. 391, pp. S208-S218, 2001.

[18] T. Tanaka, K. Fujii, and Y. Kumagae, "Comparison of biochemical characteristics of cultured fibrochondrocytes isolated from the inner and outer regions of human meniscus," Knee Surgery, Sports Traumatology, Arthroscopy, vol. 7, no. 3, pp. 75-80, 1999.

[19] G. M. Peretti, T. J. Gill, J. W. Xu, M. A. Randolph, K. R. Morse, and D. J. Zaleske, "Cell-based therapy for meniscal repair: a large animal study," American Journal of Sports Medicine, vol. 32, no. 1, pp. 146-158, 2004.

[20] C. Weinand, G. M. Peretti, S. B. Adams Jr., M. A. Randolph, E. Savvidis, and T. J. Gill, "Healing potential of transplanted allogeneic chondrocytes of three different sources in lesions of the avascular zone of the meniscus: a pilot study," Archives of Orthopaedic and Trauma Surgery, vol. 126, no. 9, pp. 599-605, 2006.

[21] M. Ohishi and E. Schipani, "Bone marrow mesenchymal stem cells," Journal of Cellular Biochemistry, vol. 109, no. 2, pp. 277282,2010

[22] R. O. C. Oreffo, C. Cooper, C. Mason, and M. Clements, "Mesenchymal stem cells lineage, plasticity, and skeletal therapeutic potential," Stem Cell Reviews, vol. 1, no. 2, pp. 169$178,2005$.

[23] U. Nöth, A. M. Osyczka, R. Tuli, N. J. Hickok, K. G. Danielson, and R. S. Tuan, "Multilineage mesenchymal differentiation potential of human trabecular bone-derived cells," Journal of Orthopaedic Research, vol. 20, no. 5, pp. 1060-1069, 2002.

[24] J. L. Cook, "The current status of treatment for large meniscal defects," Clinical Orthopaedics and Related Research, no. 435, pp. 88-95, 2005.
[25] Y. Izuta, M. Ochi, N. Adachi, M. Deie, T. Yamasaki, and R. Shinomiya, "Meniscal repair using bone marrow-derived mesenchymal stem cells: experimental study using green fluorescent protein transgenic rats," Knee, vol. 12, no. 3, pp. 217-223, 2005.

[26] A. F. Steinert, G. D. Palmer, R. Capito et al., "Genetically enhanced engineering of meniscus tissue using ex vivo delivery of transforming growth factor- $\beta 1$ complementary deoxyribonucleic acid," Tissue Engineering, vol. 13, no. 9, pp. 2227-2237, 2007.

[27] K. R. Stone, W. G. Rodkey, R. Webber, L. McKinney, and J. R. Steadman, "Meniscal regeneration with copolymeric collagen scaffolds. In vitro and in vivo studies evaluated clinically, histologically, and biochemically," American Journal of Sports Medicine, vol. 20, no. 2, pp. 104-111, 1992.

[28] J. Zellner, M. Mueller, A. Berner et al., "Role of mesenchymal stem cells in tissue engineering of meniscus," Journal of Biomedical Materials Research, Part A, vol. 94, no. 4, pp. 11501161, 2010.

[29] M. B. Pabbruwe, W. Kafienah, J. F. Tarlton, S. Mistry, D. J. Fox, and A. P. Hollander, "Repair of meniscal cartilage white zone tears using a stem cell/collagen-scaffold implant," Biomaterials, vol. 31, no. 9, pp. 2583-2591, 2010.

[30] F. Forriol, "Growth factors in cartilage and meniscus repair," Injury, vol. 40, supplement 3, pp. S12-S16, 2009.

[31] S. P. Arnoczky, "Building a meniscus: biologic considerations," Clinical Orthopaedics and Related Research, no. 367, pp. S244S253, 1999.

[32] S. Collier and P. Ghosh, "Effects of transforming growth factor beta on proteoglycan synthesis by cell and explant cultures derived from the knee joint meniscus," Osteoarthritis and Cartilage, vol. 3, no. 2, pp. 127-138, 1995.

[33] B. D. Elder and K. A. Athanasiou, "Systematic assessment of growth factor treatment on biochemical and biomechanical properties of engineered articular cartilage constructs," Osteoarthritis and Cartilage, vol. 17, no. 1, pp. 114-123, 2009.

[34] D. J. Huey and K. A. Athanasiou, "Maturational growth of self-assembled, functional menisci as a result of TGF- $\beta 1$ and enzymatic chondroitinase-ABC stimulation," Biomaterials, vol. 32, no. 8, pp. 2052-2058, 2010.

[35] C. A. Pangborn and K. A. Athanasiou, "Effects of growth factors on meniscal fibrochondrocytes," Tissue Engineering, vol. 11, no. 7-8, pp. 1141-1148, 2005.

[36] I. Martin, A. Muraglia, G. Campanile, R. Cancedda, and R. Quarto, "Fibroblast growth factor-2 supports ex vivo expansion and maintenance of osteogenic precursors from human bone marrow," Endocrinology, vol. 138, no. 10, pp. 4456-4462, 1997.

[37] T. Vincent, M. Hermansson, M. Bolton, R. Wait, and J. Saklatvala, "Basic FGF mediates an immediate response of articular cartilage to mechanical injury," Proceedings of the National Academy of Sciences of the United States of America, vol. 99, no. 12, pp. 8259-8264, 2002.

[38] M. Cucchiarini, S. Schetting, E. F. Terwilliger, D. Kohn, and H. Madry, "rAAV-mediated overexpression of FGF-2 promotes cell proliferation, survival, and $\alpha$-SMA expression in human meniscal lesions," Gene Therapy, vol. 16, no. 11, pp. 13631372, 2009.

[39] H. J. Im, C. Pacione, S. Chubinskaya, A. J. van Wijnen, Y. Sun, and R. F. Loeser, "Inhibitory effects of insulin-like growth factor-1 and osteogenic protein-1 on fibronectin fragmentand interleukin- $1 \beta$-stimulated matrix metalloproteinase- 13 expression in human chondrocytes," Journal of Biological Chemistry, vol. 278, no. 28, pp. 25386-25394, 2003. 
[40] P. Buma, N. N. Ramrattan, T. G. van Tienen, and R. P. H. Veth, "Tissue engineering of the meniscus," Biomaterials, vol. 25, no. 9, pp. 1523-1532, 2004.

[41] D. B. Fox, J. J. Warnock, A. M. Stoker, J. K. Luther, and M. Cockrell, "Effects of growth factors on equine synovial fibroblasts seeded on synthetic scaffolds for avascular meniscal tissue engineering," Research in Veterinary Science, vol. 88, no. 2, pp. 326-332, 2010.

[42] W. Petersen, T. Pufe, C. Stärke et al., "Locally applied angiogenic factors-a new therapeutic tool for meniscal repair," Annals of Anatomy, vol. 187, no. 5-6, pp. 509-519, 2005.

[43] E. Ozkaynak, P. N. J. Schnegelsberg, D. F. Jin et al., "Osteogenic protein-2. A new member of the transforming growth factor$\beta$ superfamily expressed early in embryogenesis," Journal of Biological Chemistry, vol. 267, no. 35, pp. 25220-25227, 1992.

[44] J. M. Wozney and V. Rosen, "Bone morphogenetic protein and bone morphogenetic protein gene family in bone formation and repair," Clinical Orthopaedics and Related Research, no. 346, pp. 26-37, 1998.

[45] N. Shintani and E. B. Hunziker, "Chondrogenic differentiation of bovine synovium: bone morphogenetic proteins 2 and 7 and transforming growth factor $\beta 1$ induce the formation of different types of cartilaginous tissue," Arthritis and Rheumatism, vol. 56, no. 6, pp. 1869-1879, 2007.

[46] H. Minehara, K. Urabe, K. Naruse et al., "A new technique for seeding chondrocytes onto solvent-preserved human meniscus using the chemokinetic effect of recombinant human bone morphogenetic protein-2," Cell and Tissue Banking, vol. 12, no. 3, pp. 199-207, 2010.

[47] Y. Yamada, M. Ueda, T. Naiki, M. Takahashi, K. I. Hata, and T. Nagasaka, "Autogenous injectable bone for regeneration with mesenchymal stem cells and platelet-rich plasma: tissueengineered bone regeneration," Tissue Engineering, vol. 10, no. 5-6, pp. 955-964, 2004.

[48] M. Thorwarth, F. Wehrhan, S. Schultze-Mosgau, J. Wiltfang, and K. A. Schlegel, "PRP modulates expression of bone matrix proteins in vivo without long-term effects on bone formation," Bone, vol. 38, no. 1, pp. 30-40, 2006.

[49] K. Ishida, R. Kuroda, M. Miwa et al., "The regenerative effects of platelet-rich plasma on meniscal cells in vitro and its in vivo application with biodegradable gelatin hydrogel," Tissue Engineering, vol. 13, no. 5, pp. 1103-1112, 2007.

[50] D. S. Musgrave, F. H. Fu, and J. Huard, "Gene therapy and tissue engineering in orthopaedic surgery," The Journal of the American Academy of Orthopaedic Surgeons, vol. 10, no. 1, pp. 6-15, 2002.

[51] E. Bell, "Strategy for the selection of scaffolds for tissue engineering," Tissue Engineering, vol. 1, pp. 163-179, 1995.

[52] T. G. van Tienen, G. Hannink, and P. Buma, "Meniscus replacement using synthetic materials," Clinics in Sports Medicine, vol. 28, no. 1, pp. 143-156, 2009.

[53] M. A. Sweigart and K. A. Athanasiou, "Toward tissue engineering of the knee meniscus," Tissue Engineering, vol. 7, no. 2, pp. 111-129, 2001.

[54] B. B. Mandal, S. H. Park, E. S. Gil, and D. L. Kaplan, "Multilayered silk scaffolds for meniscus tissue engineering," Biomaterials, vol. 32, no. 2, pp. 639-651, 2011.

[55] L. Meinel, V. Karageorgiou, S. Hofmann et al., "Engineering bone-like tissue in vitro using human bone marrow stem cells and silk scaffolds," Journal of Biomedical Materials Research, Part A, vol. 71, no. 1, pp. 25-34, 2004.

[56] L. Meinel, V. Karageorgiou, R. Fajardo et al., "Bone tissue engineering using human mesenchymal stem cells: effects of scaffold material and medium flow," Annals of Biomedical Engineering, vol. 32, no. 1, pp. 112-122, 2004.

[57] G. H. Altman, F. Diaz, C. Jakuba et al., "Silk-based biomaterials," Biomaterials, vol. 24, no. 3, pp. 401-416, 2003.

[58] S. M. Mueller, T. O. Schneider, S. Shortkroff, H. A. Breinan, and M. Spector, " $\alpha$-Smooth muscle actin and contractile behavior of bovine meniscus cells seeded in type I and type II collagen-GAG matrices," Journal of Biomedical Materials Research, vol. 45, no. 3, pp. 157-166, 1999.

[59] J. M. Zaleskas, B. Kinner, T. M. Freyman, I. V. Yannas, L. J. Gibson, and M. Spector, "Growth factor regulation of smooth muscle actin expression and contraction of human articular chondrocytes and meniscal cells in a collagen-GAG matrix," Experimental Cell Research, vol. 270, no. 1, pp. 21-31, 2001.

[60] S. M. Mueller, S. Shortkroff, T. O. Schneider, H. A. Breinan, I. V. Yannas, and M. Spector, "Meniscus cells seeded in type I and type II collagen-GAG matrices in vitro," Biomaterials, vol. 20, no. 8, pp. 701-709, 1999.

[61] K. Stewart, M. Pabbruwe, S. Dickinson, T. Sims, A. P. Hollander, and J. B. Chaudhuri, "The effect of growth factor treatment on meniscal chondrocyte proliferation and differentiation on polyglycolic acid scaffolds," Tissue Engineering, vol. 13, no. 2, pp. 271-280, 2007.

[62] N. J. Gunja and K. A. Athanasiou, "Additive and synergistic effects of bFGF and hypoxia on leporine meniscus cell-seeded PLLA scaffolds," Journal of Tissue Engineering and Regenerative Medicine, vol. 4, no. 2, pp. 115-122, 2010.

[63] L. C. Ionescu, G. C. Lee, G. H. Garcia et al., "Maturation statedependent alterations in meniscus integration: implications for scaffold design and tissue engineering," Tissue Engineering, Part A, vol. 17, no. 1-2, pp. 193-204, 2011.

[64] C. H. Evans and P. D. Robbins, "Possible orthopaedic applications of gene therapy," Journal of Bone and Joint Surgery, Series A, vol. 77, no. 7, pp. 1103-1114, 1995.

[65] T. G. Gerich, F. H. Fu, P. D. Robbins, and C. H. Evans, "Prospects for gene therapy in sports medicine," Knee Surgery, Sports Traumatology, Arthroscopy, vol. 4, no. 3, pp. 180-187, 1996.

[66] H. Goto, F. D. Shuler, C. Niyibizi, F. H. Fu, P. D. Robbins, and C. H. Evans, "Gene therapy for meniscal injury: enhanced synthesis of proteoglycan and collagen by meniscal cells transduced with a TGF $\beta 1$ gene," Osteoarthritis and Cartilage, vol. 8, no. 4, pp. 266-271, 2000.

[67] C. Hidaka, C. Ibarra, J. A. Hannafin et al., "Formation of vascularized meniscal tissue by combining gene therapy with tissue engineering," Tissue Engineering, vol. 8, no. 1, pp. 93105, 2002.

[68] B. Deorosan and E. A. Nauman, "The role of glucose, serum, and three-dimensional cell culture on the metabolism of bone marrow-derived mesenchymal stem cells," Stem Cells International, vol. 2011, Article ID 429187, 12 pages, 2011.

[69] S. Gavrilov, D. Marolt, N. C. Douglas et al., "Derivation of two new human embryonic stem cell lines from nonviable human embryos," Stem Cells International, vol. 2011, Article ID 765378, 9 pages, 2011.

[70] J. M. Gimble, B. A. Bunnell, L. Casteilla, J. S. Jung, and K. Yoshimura, "Phases I-III clinical trials using adult stem cells," Stem Cells International, vol. 2010, Article ID 579142, 12 pages, 2010.

[71] I. I. Katkov, N. G. Kan, F. Cimadamore, B. Nelson, E. Y. Snyder, and A. V. Terskikh, "DMSO-free programmed cryopreservation of fully dissociated and adherent human induced pluripotent stem cells," Stem Cells International, vol. 2011, Article ID 981606, 8 pages, 2011. 
[72] C. Kelly, C. C. S. Flatt, and N. H. McClenaghan, "Stem cellbased approaches for the treatment of diabetes," Stem Cells International, vol. 2011, Article ID 424986, 8 pages, 2011.

[73] E. A. Kimbrel and S.-J. Lu, "Potential clinical applications for human pluripotent stem cell-derived blood components," Stem Cells International, vol. 2011, Article ID 273076, 11 pages, 2011.

[74] E. Mansilla, V. Díaz Aquino, D. Zambón et al., "Could metabolic syndrome, lipodystrophy, and aging be mesenchymal stem cell exhaustion syndromes?" Stem Cells International, vol. 2011, Article ID 943216, 10 pages, 2011.

[75] R. T. Mitsuyasu, J. A. Zack, J. L. Macpherson, and G. P. Symonds, "Phase I/II Clinical Trials Using Gene-Modified Adult Hematopoietic Stem Cells for HIV: lessons Learnt," Stem Cells International, vol. 2011, Article ID 393698, 8 pages, 2011.

[76] H. Narimatsu, "Immune reactions following cord blood transplantations in adults," Stem Cells International, vol. 2011, Article ID 607569, 6 pages, 2011.

[77] A. D. Petropoulou and V. Rocha, "Risk factors and options to improve engraftment in unrelated cord blood transplantation," Stem Cells International, vol. 2011, Article ID 610514, 8 pages, 2011.

[78] C. Tekkatte, G. P. Gunasingh, K. M. Cherian, and K. Sankaranarayanan, "'Humanized" stem cell culture techniques: the animal serum controversy," Stem Cells International, vol. 2011, Article ID 504723, 14 pages, 2011.

[79] C. M. Teven, X. Liu, N. Hu et al., "Epigenetic regulation of mesenchymal stem cells: a focus on osteogenic and adipogenic differentiation," Stem Cells International, vol. 2011, Article ID 201371, 18 pages, 2011.

[80] T. J. Wyatt, S. L. Rossi, M. M. Siegenthaler et al., "Human motor neuron progenitor transplantation leads to endogenous neuronal sparing in 3 models of motor neuron loss," Stem Cells International, vol. 2011, Article ID 207230, 11 pages, 2011.

[81] J. Fiedler, G. Röderer, K.-P. Günther, and R. E. Brenner, "BMP2, BMP-4, and PDGF-bb stimulate chemotactic migration of primary human mesenchymal progenitor cells," Journal of Cellular Biochemistry, vol. 87, no. 3, pp. 305-312, 2002. 

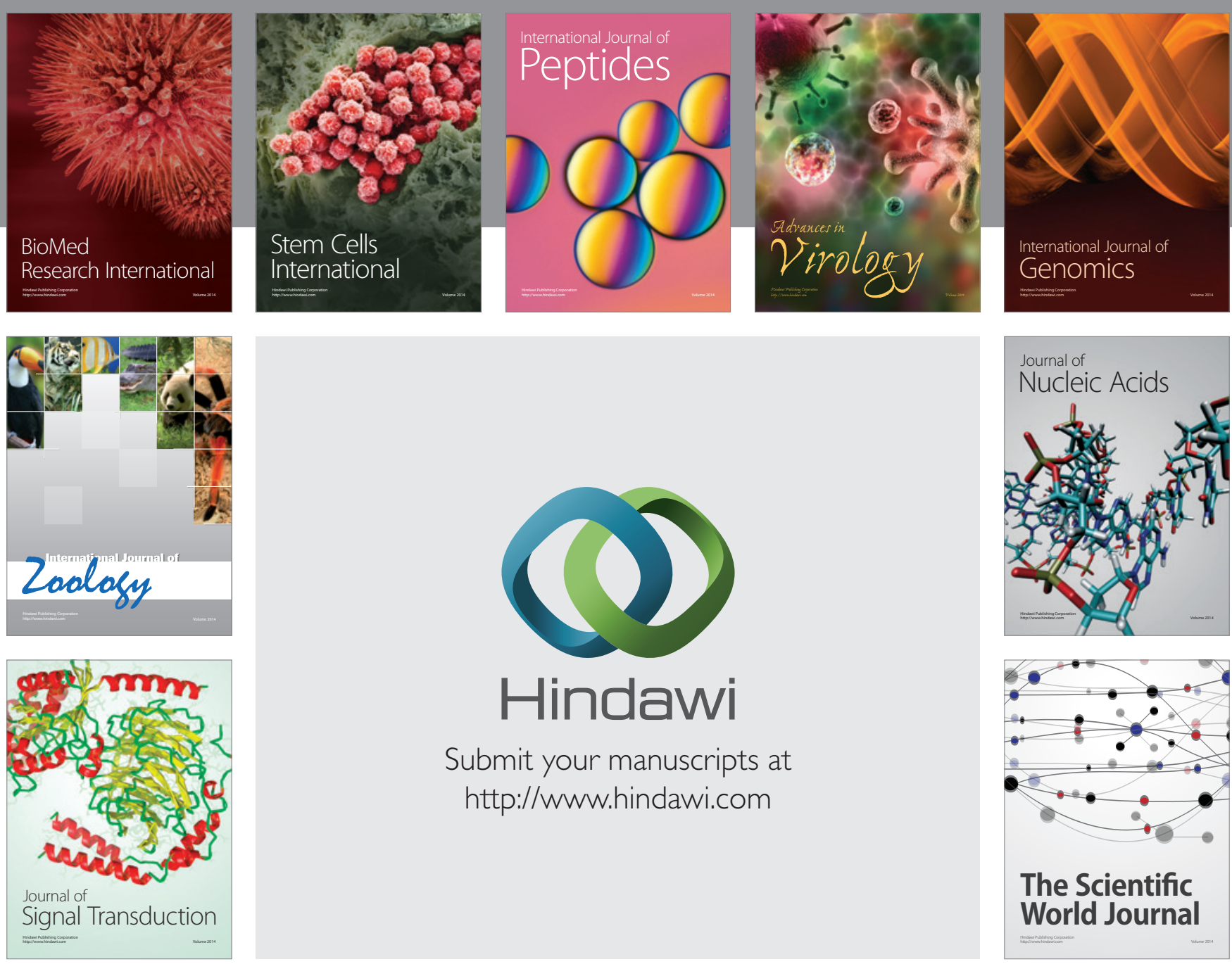

Submit your manuscripts at

http://www.hindawi.com
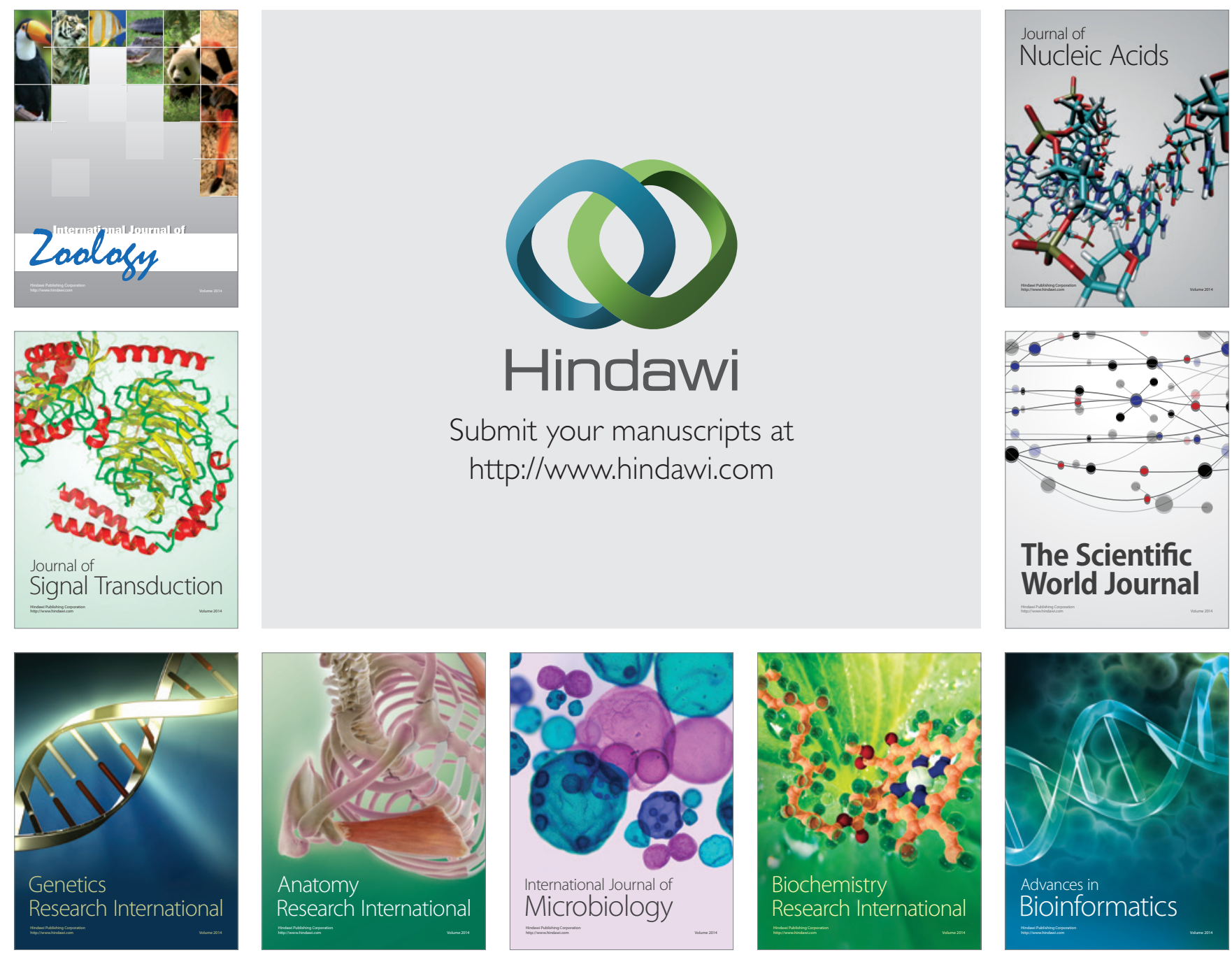

The Scientific World Journal
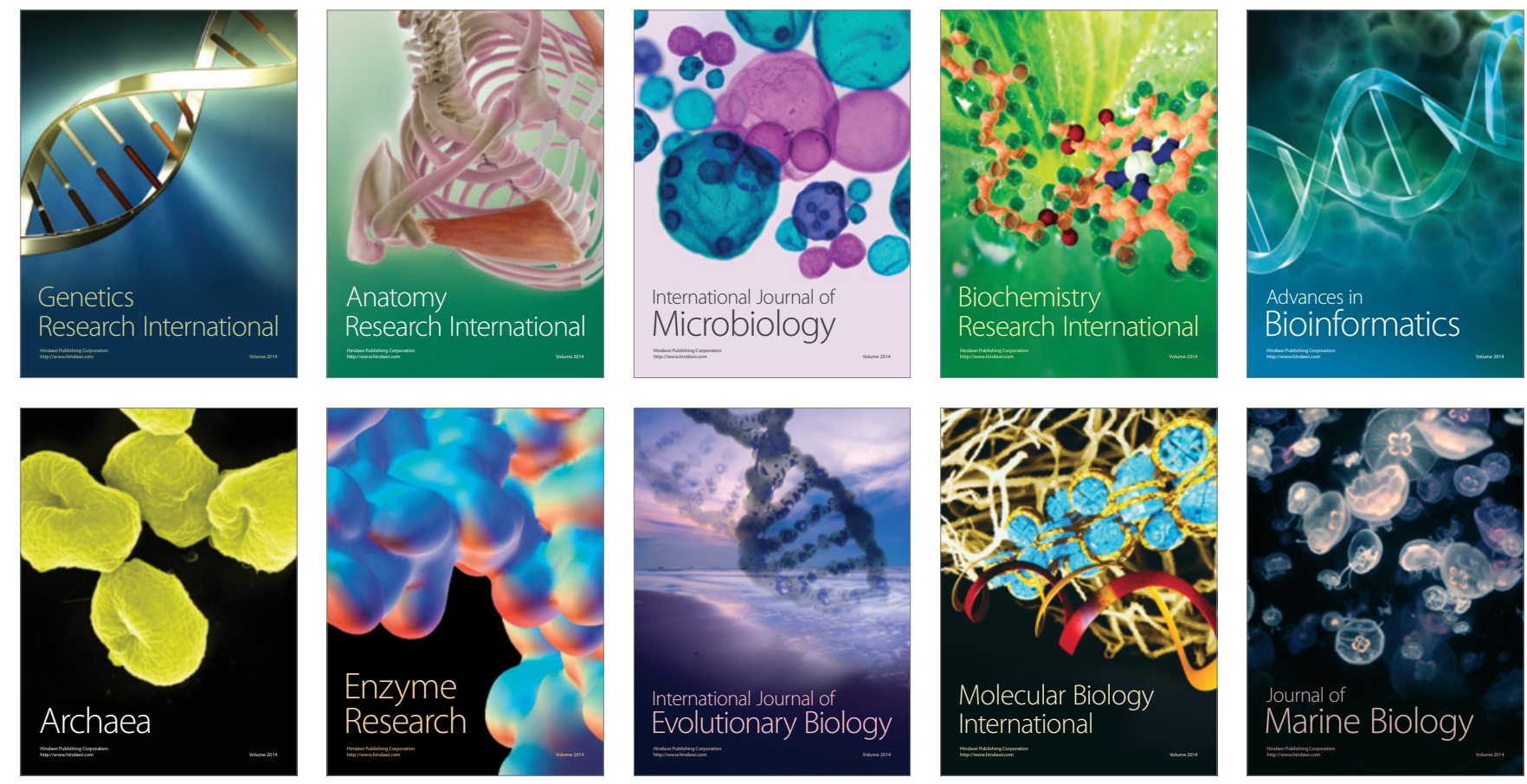